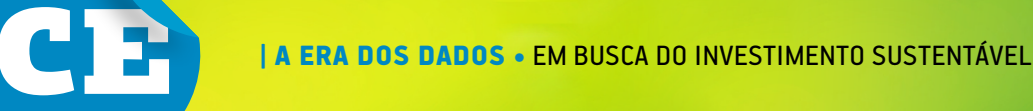

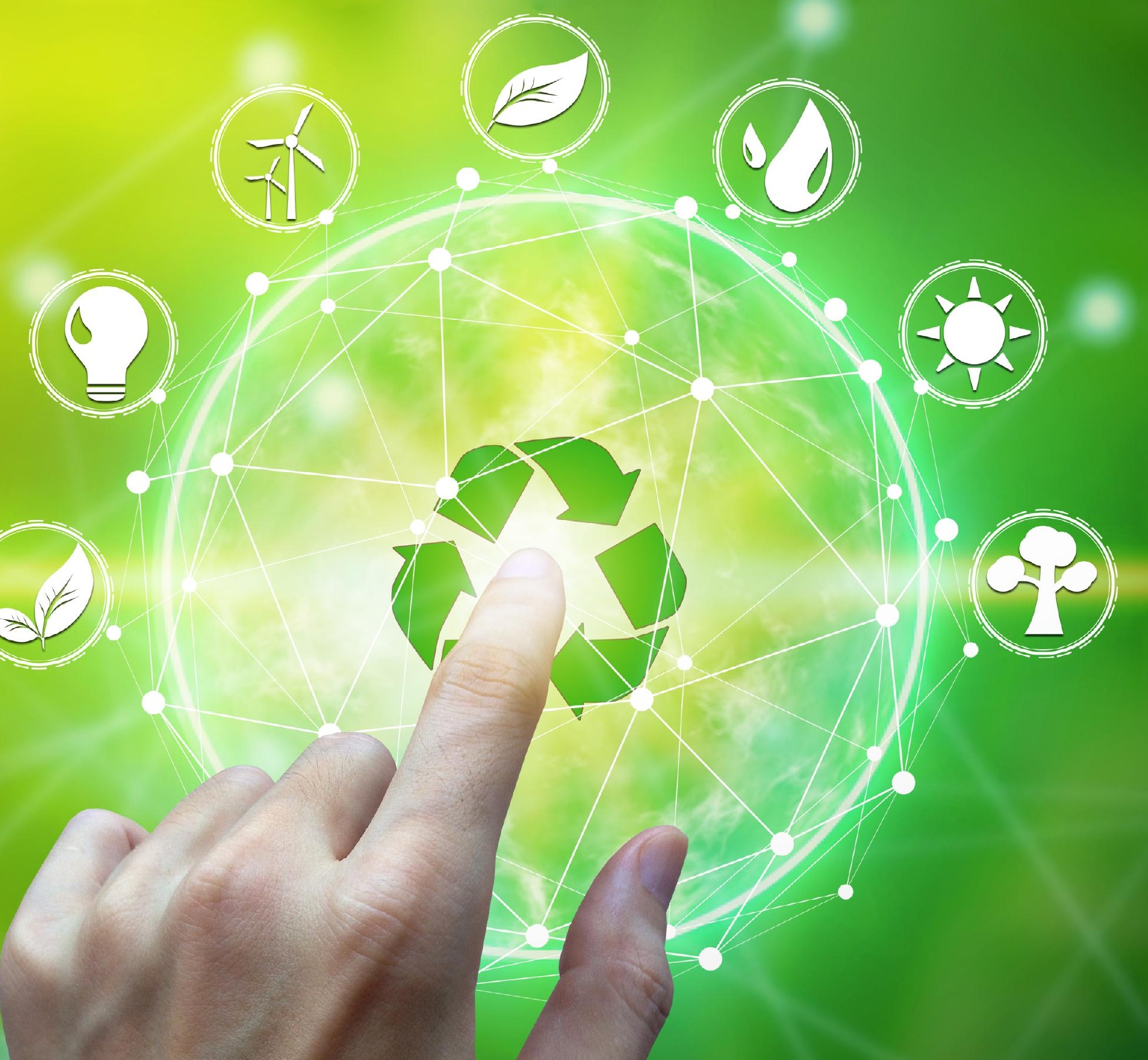




\section{EM BUSCA DO INVESTIMENTO SUSTENTÁVEL}

\section{Como a era dos dados abre novas perspectivas}

\section{para a identificação de negócios afinados com a sustentabilidade.}

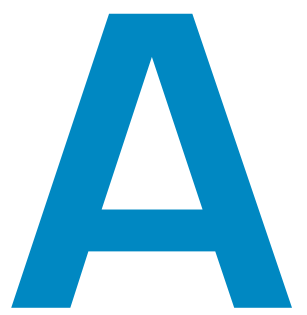

era dos dados promete enorme avanço em sistemas sustentáveis de produção e consumo. Há de fato motivos para otimismo, mas a efetivação desse potencial depende de como as novidades tecnológicas vão ser utilizadas para responder a uma pergunta crucial para investidores, empreendedores e gestores: onde alocar capitais em sintonia com a grande transformação que acontece no ambiente de negócios? Ou, em outras palavras, como identificar e priorizar negócios com base em sua capacidade de contribuir com a construção de uma economia verde e inclusiva e, ao mesmo tempo, se beneficiar dela?

Para que as tecnologias peculiares da era dos dados ajudem a responder a essa pergunta, é preciso combinar, de um lado, a capacidade de captura, processamento e análise de dados e, de outro, referenciais analíticos e metodologias capazes de indicar-com objetividade, consistência e boa dose de certeza - as relações entre as atividades empresariais e os impactos positivos e negativos que estas geram para a sociedade, o meio ambiente e suas demais partes interessadas (confira uma proposta de modelo geral de avaliação no box deste artigo). O ponto de partida, naturalmente, são as iniciativas que desde os anos 1990 vêm sendo desenvolvidas para levantar indicadores de sustentabilidade nas organizações. Essas iniciativas, porém, foram em sua maioria criadas em um contexto anterior à abundância de dados e ao acesso viável a grande poder de processamento. Por isso, em geral, baseiam-se em questionários, relatórios e/ou pesquisas especializadas, e ainda não incorporam possibilidades que as novas tecnologias podem viabilizar, como o uso de algoritmos e ferramentas estatísticas para captura e análise de informações disponíveis na internet ou de dados gerados por sensores de Internet of Things (IoT) e por transações on-line.

Esse é um desafio que enfrentam os mais conhecidos instrumentos para avaliação da sustentabilidade empresarial hoje em uso, como os referenciais para relatos autodeclaratórios - a exemplo das diretrizes da Global Reporting 
Initiative (GRI), ou do International Integrated Reporting Council (IIRC), e/ou ainda do Pacto Global da Organização das Nações Unidas (ONU). O mesmo aplica-se também aos instrumentos que calculam indicadores baseados em questionários, quer para o cálculo de métricas por critérios ESG (sigla em inglês para ambiental, social e de governança) utilizados por atores do mercado financeiro, quer para autoavaliação (como os Indicadores Ethos de Responsabilidade Social), avaliações de impacto (B Impact Assessment), ou ainda para processos de rankeamento ou seleção, como os empregados por índices de sustentabilidade criados por bolsas de valores, a exemplo do Dow Jones Sustainability Index (DJSI), da Bolsa de Valores de Nova York, e do Índice de Sustentabilidade Empresarial (ISE) da B3, no Brasil.

Nesse contexto, merece especial atenção a atual iniciativa desta última - que visa incorporar novos componentes com o uso de Big Data Analytics e Inteligência Artificial (BDAI), ao processo de composição e gestão da carteira em que se baseia o ISE B3.

\section{BIG DATA PARA UM PORTFÓLIO MAIS SUSTENTÁVEL}

Quarto índice desse tipo no mundo, o ISE B3 tem uma história de pioneirismo e ousadia. Trata-se de um índice financeiro que mede a valorização de uma carteira teórica formada por ações de companhias listadas na B3 que se destacam por adotar políticas e práticas voltadas à sustentabilidade. A seleção dessas empresas é feita anualmente e resulta da combinação entre três elementos:

- um questionário, que gera uma avaliação quantitativa das empresas respondentes;

- uma análise amostral de evidências das respostas dadas pelas empresas, que gera uma avaliação qualitativa;

- uma avaliação abrangente, feita pelo Conselho Deliberativo do ISE, que decide as empresas que serão incluídas na carteira, levando em conta as duas outras avaliações mencionadas, combinadas ao julgamento e à experiência do conjunto de 11 conselheiros, representantes de organizações nacionais e internacionais de relevância tanto no mercado financeiro quanto no campo da sustentabilidade. A metodologia e o questionário do ISE B3 vêm sendo construídos ao longo de 15 anos de atividades, que incluem a revisão por especialistas nos temas enfocados e, também, processos anuais de consulta pública, com participação tanto de empresas quanto de investidores e de outros stakeholders. Traduzem, assim, a agenda de sustentabilidade empresarial no país.

\section{A bolsa de valores brasileira [B3] iniciou um projeto para incorporar ao seu modelo de índice de sustentabilidade empresarial métricas objetivas extraídas do big data.}

Em sintonia com as mudanças em curso, o ISE B3 está empenhado em incorporar a esse processo o uso de tecnologias trazidas pela era de dados. Em 2018, uma parceria entre a B3, o Columbia Center on Sustainable Investment (CCSI), da Columbia University, e o Centro de Estudos em Sustentabilidade, da Fundação Getulio Vargas (FGVces), resultou em uma série de três debates multidisciplinares envolvendo representantes de 53 organizações do Brasil e do exterior, visando identificar o estado da arte e as principais tendências e desafios no uso de BDAI para avaliar a contribuição das empresas para os Objetivos do Desenvolvimento Sustentável (ODS). O registro completo dos trabalhos está disponível em bit.ly/BDAI4SD-2018 e inclui, por exemplo, um atualíssimo guia de fornecedores de métricas ESG com uso de BDAI.

Avançando sobre os conhecimentos assim acumulados, a B3 lançou em abril de 2019 uma iniciativa para a construção do Léxico ISE B3 (LISE): uma solução tecnológica pensada para a realidade brasileira e que objetiva apoiar empresas, investidores e outros stakeholders no uso de informações públicas para avaliação da sustentabilidade empresarial e da relação desta com os ODS e as métricas ESG disponíveis no mercado. Prevista para terminar em dezembro de 2020, a fase inicial desse projeto prevê a construção da metodologia e dos instrumentos tecnológicos básicos e incluirá a interlocução com empresas e outras partes interessadas. Para saber mais e participar, visite iseb3.com.br.

Em termos práticos, o LISE ambiciona contribuir com um conjunto de informações adicionais às hoje utilizadas pelo Conselho Deliberativo do ISE B3 na escolha e no monitoramento das empresas que comporão a carteira do índice a cada ano. Para isso, deverá produzir relatórios contendo indicadores objetivos para a avaliação do desempenho e/ou relacionamento de uma empresa com 


\section{UM MODELO PARA AVALIAR A SINERGIA ENTRE O NEGÓCIO E A SUSTENTABILIDADE}

Em um cenário de tantas e tão rápidas transformações, torna-se cada vez mais difícil discernir os negócios mais promissores, ainda mais quando praticamente todas as empresas tentam, de uma forma ou de outra, vestir os figurinos de "sustentável" e "inovadora". Uma forma possivelmente eficaz de ultrapassar essa cortina de fumaça e separar o joio do trigo é a análise da sinergia entre o negócio que se deseja avaliar e as demandas da sustentabilidade. Esse modelo combina um cenário e duas variáveis. Como cenário, é considerado o contexto emergente: um ambiente de negócios caracterizado pela transparência (ampliada pela era dos dados) e pela exigência de sustentabilidade. Como variáveis, de um lado, devese considerar a vantagem relativa que, no contexto emergente, se prevê para o negócio em análise e, de outro lado, a previsível contribuição desse negócio para a sociedade, em linha com o contexto emergente (veja no diagrama).

\section{DIAGRAMA DE ANÁLISE DE NEGÓCIOS MAIS E MENOS PROMISSORES*}

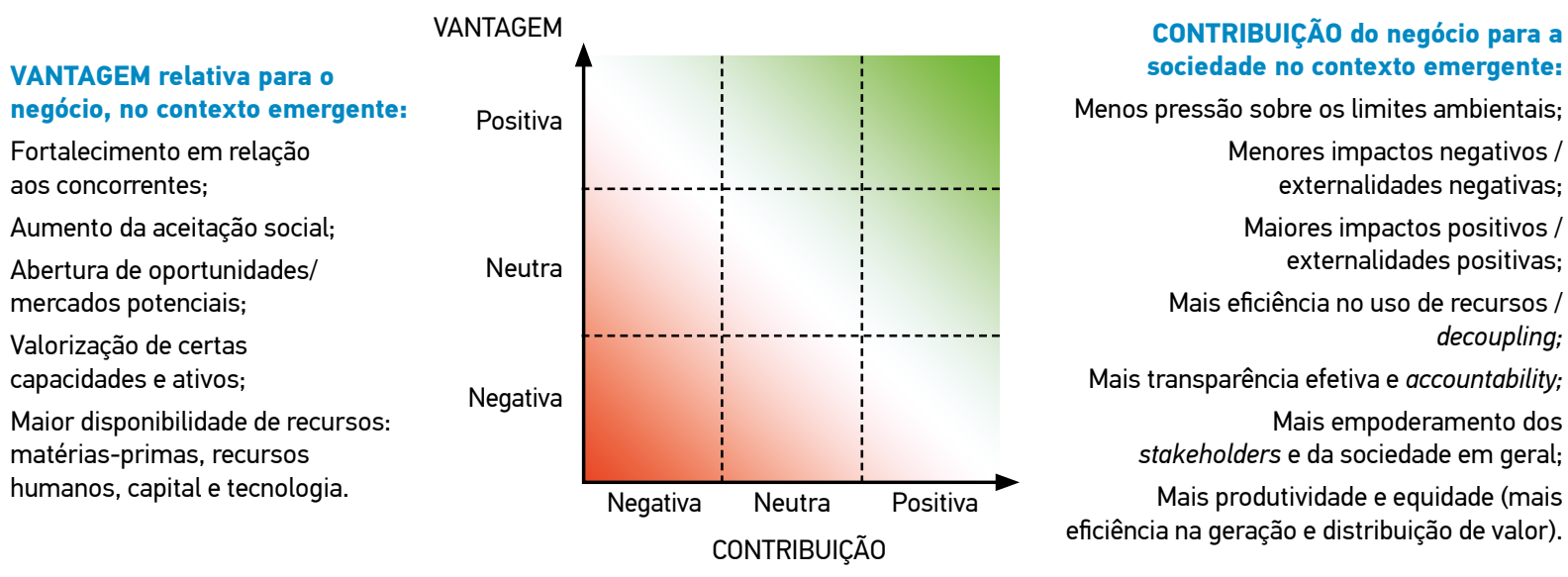

*O DIAGRAMA APRESENTA POSSÍVEIS CRITÉRIOS PARA AVALIAÇÃO DAS VARIÁVEIS, CUJA COMBINAÇÃO GERA PELO MENOS NOVE QUADRANTES, DE MODO QUE CADA VARIÁVEL SEJA CONSIDERADA NEGATIVA, NEUTRA OU POSITIVA. A PREDOMINÂNCIA DO TOM VERDE INDICA NEGÓCIOS MAIS PROMISSORES, E A DO TOM VERMELHO, NEGÓCIOS A SEREM EVITADOS.

temas da sustentabilidade. Esses indicadores serão produzidos pela combinação de informações públicas com manifestações das próprias empresas, extraídas tanto de textos (notícias, relatórios, websites e outros documentos) quanto de fontes de dados estruturadas (registros públicos e legais, relatórios contábeis etc.). É planejado que os resultados desse sistema serão traduzidos em dois insumos para os processos anuais do ISE B3: um relatório de transparência ativa, que abrangerá períodos de tempo predeterminados (ano, semestre, trimestre); e um sistema de monitoramento cotidiano das empresas integrantes da carteira em vigor.

\section{POTENCIAIS E CUIDADOS}

Concluindo, é importante destacar o momento que vivemos: estamos apenas no início de uma radical transformação tecnológica e produtiva, que trará consigo profundas mudanças sociais e culturais. Há um enorme potencial para a geração de impactos positivos, mas é também necessário cuidado com as possíveis consequências indesejáveis (os impactos negativos) que tais modificações nos padrões de produção e consumo poderão gerar, tanto sobre o meio ambiente quanto sobre os seres humanos. Dirigentes empresariais e investidores têm nesse processo papel essencial, pois suas decisões definirão, em grande medida, o balanço desses impactos. Assim, é de fundamental importância que rapidamente conheçam e utilizem instrumentos que os ajudem a se orientar nesse novo e fascinante capítulo do desenvolvimento humano.

\footnotetext{
PARA SABER MAIS:

Volans. Breakthrough business models: exponentially more social, lean, integrated and circular, 2016. Disponivel em: volans.com/wp-content/uploads/2016/09/Volans Breakthrough-Business-Models_Report_Sep2016.pdf

Unep Finance Initiative, United Nations Global Compact. The SDG investment case: principles for responsible investment, 2017. Disponivel em: unpri.org/download?ac=5909 Aron Belinky. Da Empresa cowboy à astronauta. GV-executivo, v.16, n.5, 2017. Disponivel em: bit.ly/cowboy-astronauta

Aron Belinky. A Terceira geração da sustentabilidade empresarial. GV-executivo, v.15, n.2, 2016. Disponivel em: http://bit.ly/3aGeracao
}

ARON BELINKY > Professor da FGV EAESP > aron.belinky@fgv.br 